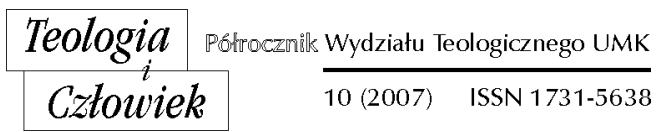

KS. IRENEUSZ CELARY*

KATOWICE

\title{
DIE SEELSORGERISCHE MISSION DER KIRCHE GEGENÜBER ABHÄNGIGER PERSONEN
}

Die durch die Gaben ihres Gründers ausgestattete. Kirche bewahrt Heute getreu sein Gebot der Liebe, der Demut und des Gehorsams. Wie das Konzildokument feststellt: „erhält sie die Mission der Verkündung und Verbreitung des Göttlichen und Christlichen Königsreiches unter den Völkern und bildet den Ansatz dieses Königreiches auf Erden" (KK 5).

Darum bleibt die Kirche, ermuntert durch das Beispiel von Jesus, immer für die Bedürfnisse des Menschen offen ${ }^{1}$. Die erlösende Mission betrifft nicht nur die Ewigkeit des Menschen aber genauso die Fülle seiner vergänglichen Entwicklung ${ }^{2}$. Demnach bemüht sich die Kirche, schreitend in Jesu Christi Fußstapfen, der Herausforderung jederzeit zu wachsen.

Dieses Bedürfnis stützt sich auch u.a. auf der stetigen Verwirklichung des Dienstes Christi für Menschen die von Alkohol, Zigaretten und anderen psychoaktiven Mitteln abhängig sind ${ }^{3}$.

* Ks. dr hab. Ireneusz Celary jest pracownikiem naukowym Wydziału Teologicznego Uniwersytetu Śląskiego w Katowicach.

${ }^{1}$ Por. J. Majka, Kościót jako dalszy ciagg miłosierdzia Chrystusa, w: Ewangelia mitosierdzia, red. W. Granat, Poznań 1970, s. 191-194.

${ }^{2}$ Por. Formacja postaw moralnych w Narodzie, w: II Polski Synod Plenarny. Teksty robocze, Warszawa 1991, s. 377.

${ }^{3}$ Zob. Cz. Cekiera, Toksykomania: narkomania, lekomania, alkoholizm, nikotynizm, Warszawa 1985. 
Die Verwirklichung dieser Aufgabe im Rahmen der allgemeinen seelsorgerischen Tätigkeit erfordert ein spezielles Engagement der geistlichen und säkularen Personen.

Dieses außergewöhnliche Engagement erhielt in der pastoralen Theologie die Bezeichnung der Seelsorge Abhängiger Personen.

Die Wahrheit, die sich unter dem Namen verbirgt ist jegliche evangelisatorische Tätigkeit der Kirche, deren Ziel das zu Hilfekommen für die Personen ist, die oft auf den Rand der Gesellschaft verschoben werden, um sie vor weiterer Vertiefung der Abhängigkeit zu bewahren und ihnen zur Rückkehr in das normale Leben zu helfen ${ }^{4}$.

Die seelsorgerische Sorge der Kirche gegenüber dieser Personen wird daher so geführt, dass sie sich von neuem in Gott über den Verlust der verlorenen Würde bewusst werden ${ }^{5}$. Nach der christlichen Lehre besitzt nämlich jeder, durch Gott geschaffene, Mensch das Lebensziel und den freien Willen $\mathrm{zu} \mathrm{Ihm}$ zu streben'.

Durch die Zusammenarbeit mit der Gnade kann der Mensch die Fülle seiner Menschlichkeit erlangen. Die Abhängigkeit des Menschen von Alkohol oder Drogen bewirkt dagegen die Erniedrigung seiner Würde. Bei abhängigen Menschen wird die Freiheit bedeutend begrenzt, sie geraten in die Gefangenschaft.

\section{SITUATION DER ABHÄNGIGEN MENSCHEN IN POLEN - ERSCHEINUNGSBILD}

Nach Meinung von Pfr. Prof. Cz. Cekiera, des Wegbereiters der Prophylaxe der Abhängigkeit in Polen hat die, die von psychotropischen Mitteln abhängige, gesellschaftliche Pathologie, hauptsächlich in den letzten Jahren des vergangenen Jahrhunderts, weite Kreise gezogen. Es machen sie vor al-

${ }^{4}$ Zob. Z. Gaś, Psychologiczne aspekty uzależnienia od nikotyny, w: Palenie tytoniu a zdrowie, red. J. Milanowski, J. Błędowski, Lublin 1995, s. 163-178.

${ }^{5}$ Zob. Kongregacja Nauki Wiary, Instrukcja o niektórych aspektach teologii wyzwolenia, w: W trosce o petnię wiary, Tarnów 1995, s. 215-235.

${ }^{6}$ Por. U. Dudziak, Człowiek uzależniony: rodzaje $i$ skutki uzależnień, motywy pomocy, w: Środowiska specjalnej troski. Wspólnie możemy im pomóc!, red. M. Kalinowski, Lublin 2003, s. $189-190$.

7 Por. Jan Paweł II, Orędzie na Światowy Dzień Pokoju, Rzym 1985, s. 3.

${ }^{8}$ Por. Cz. Cekiera, Uzależnienie od środków psychotropowych deformacja obrazu Boga w człowieku, w: Ocalić w człowieku obraz i podobieństwo Boże. III Kongres Trzeźwości na Podhalu (31 V-2 VI 2002), red. E. Iwulska, M. Jagła, Ludźmierz 2002, s. 29. 
lem Alkoholabhängigkeit ${ }^{7}$, Drogen ${ }^{8}$ - und Nikotinsucht ${ }^{9}$ aus. Sie ist nicht nur für die einzelne Person aber auch für das ganze Volk eine große Bedrohung.

Darum gehört sie auch mit aller Gewissheit zu den am meisten brennenden gesellschaftlichen Problemen unserer Zeit und bestimmt eine dringlichste politische, wirtschaftliche, moralische sowie auch seelsorgerische Herausforderung ${ }^{10}$.

Heute ist das gesellschaftliche Bewusstsein in dieser Beziehung - nach Pfr. Prof. Cekiera - größer und keiner bestreitet schon seine Existenz. Besonders beängstigend ist die Allgemeinheit der Abhängigkeit und die durch den Geist des Liberalismus verstärkte Toleranz dieses Phänomens. „Wir leben in einer Gesellschaft - meint Professor - in der der Konsum von Alkohol und das Rauchen ein Brauch so angenommen und allgemein ist, dass der Abstinent eher als unnormal erscheint wie eine trinkende Person" ${ }^{\prime 11}$.

Es ist ein Problem, dass selbst Personen die besonders zur gesellschaftlichen Autorität prädispositioniert sind, wie Ärzte, Lehrer, Priester, die Schar der Abhängigen vergrößern.

Es kommt vor, dass wir so weit die Sensibilität unserer Gewissen auf dieses Problem geschwächt haben, dass wir auf Alkohol, Zigaretten und andere Genussmittel in öffentlichen Stellen greifen und dabei nichts ungebührliches sehen ${ }^{12}$.

Zufolge zunehmenden Konsums, besonders von Alkohol droht der polnischen Gesellschaft die Gefahr einer biologischen Degeneration und Verlust der moralischen Kondition ${ }^{13}$. Die Jugend ${ }^{14}$ und sogar Schulkinder ${ }^{15}$ werden zu Alkohol verführt ${ }^{16}$.

${ }^{9}$ Por. J. E. Zejda, Środowiskowe narażenia na dym tytoniowy a układ oddechowy u dzieci w Polsce, w: Palenie tytoniu a zdrowie. II Ogólnopolska Konferencja Naukowa poświęcona pamięci prof. F. Venuleta, Warszawa 1999, s. 19.

${ }^{10}$ Zob. J. Glemp, Charakterystyka zadania Kościoła w III Rzeczpospolitej w świetle II Polskiego Synodu Plenarnego, w: Kościót w Polsce wobec potrzebujących, red. M. Chmielewski, Lublin 1994, s. 25-34.

${ }^{11} \mathrm{Cz}$. Cekiera, Psychologiczne $i$ profilaktyczne aspekty uzależnień od środków psychotropowych, w: O godność osoby ludzkiej, red. L. J. Kułakowski, I. Antolak-Kułakowska, Radom 2002, s. 50.

${ }^{12}$ Por. U. Dudziak, Człowiek uzależniony..., s. 184.

${ }^{13}$ Por. S. Luft, Medycyna pastoralna, Warszawa 2002, s. 52.

${ }^{14}$ Zob. J. Śledzianowski, Uzależnienia wśród dzieci i młodzieży w Polsce na przykładzie województwa świętokrzyskiego, w: O godność osoby..., s. 143-166.

${ }^{15}$ Por. S. Luft, Medycyna..., s. 54-55.

${ }^{16}$ Zob. I. Wald, J. Morawski, J. Moskalewicz, T. Szydłowska, II Raport o polityce wobec alkoholu. Zespót Ekspertów do Spraw Przeciwdziatania Alkoholizmowi przy Ministerstwie Zdrowia i Opieki Społecznej, Warszawa 1990. 
Er führt auch zu Verschwendung, Pfuscherei, Faulheit, sexualen Sittenwidrigkeit ${ }^{17}$ und der Zerschlagen der Familien

(Zunahme der Ehescheidungen). Die Gründe dieser Pathologie sind sehr kompliziert. Man kann hier auf kulturelle, gesellschaftlich-ökonomische, biologische, psychologische und erbliche Bedingungen aufmerksam machen ${ }^{18}$.

Missbrauch von Alkohol und anderer Abhängigkeitsmittel bewirkt auch unberechenbare wirtschaftliche Verluste. Die moralischen und kulturellen Verluste die von diesem Missbrauch verursacht sind ziehen auch wirtschaftliche Verluste nach sich ${ }^{19}$.

Die durch Missbrauch von Alkohol und anderer Abhängigkeitsmittel verursachte Pathologie hat großen Einfluss auf eine Desorganisation und Destruktion des religiösen Lebens, der Familien- und Arbeitsumgebung, bewirkt eine Herabsetzung des Kulturniveaus der Jugend und ist auch oft kriminell beeinflussender Faktor (Randale, Straftaten, Verbrechen, Autounfälle usw. $)^{20}$.

\section{DIE FOLGEN DER ABHÄNGIGKEIT}

Die Stellung einer Diagnose der Situation wie auch die Bereitschaft zur Hilfe für die abhängigen Menschen bedürfen ein Wisse über die Art und Folgen der Abhängigkeit. Die Abhängigkeit ist mit einer starken und unwiderstehlichen Gewohnheit zur Einnahme bestimmter Stoffe, zum rauchen von Tabak oder mit Ausführung bestimmter Tätigkeiten, verbunden.

Alle Abhängigkeiten bewirken in der physikalischen, psychischen, geistigen und gesellschaftlichen Sphäre negative Folgen ${ }^{21}$.

Die Medizin kennt 25 Gruppen von durch Tabak verursachte Krankheiten von denen Krebs die ernsthaft zu nehmende is $\mathrm{t}^{22}$.

Chronischer Missbrauch von Alkohol führt zu Leberzirrhose. Bei Alkoholikern kennt man auch spezifische Formen von Störungen der Psyche

${ }^{17}$ Por. J. Dobson, Zasady nie sa dla tchórzy, Warszawa 1993, s. 189; zob. U. Dudziak, Seksualność a polityka od socjalizmu do liberalizmu, Torun 1999.

${ }^{18}$ Zob. J. Moskalewicz, D. Wiszejko, Zmniejszenie $i$ zmiana struktury spożycia alkoholu oraz zmniejszenie szkód zdrowotnych spowodowanych alkoholem, Alkoholizm i Narkomania 35 (1999), s. 149-163.

${ }^{19}$ Por. U. Dudziak, Człowiek uzależniony..., s. 188.

${ }^{20}$ Zob. I. Wald (i inni), dz. cyt.

${ }^{21}$ Zob. Cz. Cekiera, Psychoprofilaktyka uzależnień oraz terapia i resocjalizacja osób uzależnionych, Lublin 1993.

${ }^{22}$ Por. W. Zatoński, Rzuć palenie razem z nami, Warszawa 1999, s. 141. 
wie verschiedener Psychosen, Schizophrenie $u_{s w}^{23}$. Die Einnahme von Rauschgift führt durch schwere Störungen im Atmungs-, Nahrungs-, Herz-Kreislauf-, und Nervensystem zur allmählichen Auszehrung des Körpers und zur Psychodegradation ${ }^{24}$.

Die psychotischen Folgen der Abhängigkeit sind u.a.: Gefühlsstörungen, Apathie oder Überaktivität, Neurosen, Behinderung der harmonischen Intellektual- und Persönlichkeitsentwicklung, Schwächung der Vorstellungskraft, zwischenmenschliche Konflikte, Kontaktverlust, psychische Störungen. Öffentliches sich der Sucht hingeben hat auch einen negativen Einfluss auf die Erziehung.

Der abhängige Mensch wird in Religionsfragen gleichgültig, verliert die Empfindsamkeit des Gewissens, vernachlässigt das Gebet, wendet sich von Gott ab, zerstört das Gottesbild in sich, geht vom Weg der Erlösung ab ${ }^{25}$.

Die zahlreichen negativen Folgen der Abhängigkeit erfordern darum eine entschlossene Gegenwirkung. Das Problem der Abhängigkeit ist eine Belastung für die ganze Gesellschaft. In der Prophylaxe der Abhängigkeit findet nicht nur der Arzt aber auch jeder Mensch guten Willens seinen Platz und seine Form der Wirkung. Wesentlich ist auch das Engagement der Kirchen, Glaubensgemeinschaften und gesellschaftlichen Organisationen ${ }^{26}$.

Davon vorausgehend, wird die Sorge um eine Verwirklichung des ausgefüllten evangelischen Lebens, nach der Lehre des II Vatikanischen Konzils, besonders angesichts des immer steigen Alkoholkonsums und anderer Abhängigkeitsmittel (hauptsächlich Drogen) in der polnischen Gesellschaft, durch die Kirche in Polen als wichtige seelsorgerische Aufgabe geachtet ${ }^{27}$.

Die Seelsorge der Abhängigen, muss demnach, nach früheren Erfahrungen die Zeichen der Zeit erkennen und auf die Probleme der Abhängigen antworten, sie muss dabei auf die Errungenschaften im Bereich der Medizin und Psychologie zugreifen. Es wird geboten der abhängigen oder bedrohten Person zu suggerieren, sich beim Facharzt untersuchen zu lassen ${ }^{28}$.

${ }^{23}$ Por. Cz. Cekiera, Psychologiczne i profilaktyczne aspekty..., s. 54.

${ }^{24}$ Por. tenże, Uzależnienie od środków psychotropowych..., s. 24-25.

${ }^{25}$ Por. U. Dudziak, Człowiek uzależniony..., s. 188.

${ }^{26}$ Tamże.

${ }^{27}$ Przypomniał o tym również papież Jan Paweł II, który 18 sierpnia 2002 r. w Krakowie na Błoniach tak mówił: „Nadszedł czas, żeby Chrystusowe przesłanie dotarło do wszystkich, zwłaszcza tych, których człowieczeństwo i godność zadaje się zatracać w misterium iniquitatis [nieprawości - przypis Autora] ... Potrzeba «wyobraźni miłosierdzia», aby ... nie odwracać się od chłopca i dziewczyny, którzy zagubili się w świecie uzależnień".

${ }^{28}$ Por. S. Luft, Medycyna..., s. 65-66; zob. Przestanie nadziei. Przewodnik dla duszpasterstwa trzeźwości, red. M. Drzewiecki, Warszawa 1993. 


\section{FORMEN DER SEELSORGE DER ABHÄNGIGEN}

Die Kirche als Gemeinschaft leider mit leidenden mit und ruft zur gegenseitigen Sorge auf (vrg. 2 Kor 12, 25-26). In der Ausfüllung seiner Mission richtet sich die kirchliche Gemeinschaft zu allererst nach den in der Offenbarung enthaltenen Grundsätzen, gestützt auf die biblischen Voraussetzungen und leitet die allgemeinen pastoralen Hinweise ${ }^{29}$.

Die zweite wichtige Form der Seelsorge der Abhängigen ist die Ausübung des Kultes, also die Liturgie. Besonders im Laufe des liturgischen Jahres nimmt die Kirche in Polen viele Initiativen in diesem Bereich auf.

Sie sind mit bestimmten Liturgiezeiträumen verbunden ${ }^{30}$. Die wichtigsten zyklischen Aktionen sind mit dem Advent, der Fastenzeit und dem Monat August verbunden ${ }^{31}$.

Auf dieser Plattform muss man sich hauptsächlich auf die Erziehung für eine Teilnahme an religiösen Praktiken Konzentrieren.

Der Missbrauch von Alkohol und das Greifen nach anderen psychotropischen Mitteln ist eine Sünde und daher zerreist er die Verbindung mit Gott. Der Mensch gewinnt durch die heiligen Sakramente die verlorene Würde des Kindes Gottes wieder zurück und bekommt eine Verstärkung eines Erlebens in Stand der Gnade. Es ist bewiesen, dass liturgische Ereignisse Gelegenheit zu Familientreffen sind und diese sind verbunden mit Konsum und vielmals auch mit Missbrauch alkoholischer Getränke ${ }^{32}$.

Das empfangen der heiligen Sakramente durch Kinder und Jugendliche kann man mit Abstinenzbeschlüssen als Opfer in verschiedenen Intentionen verbinden ${ }^{33}$.

Manche Zeiträume des Kirchenjahres sind auch mit Durchführung von Exerzitien verbunden. In vielen Diözesen waren und sind Exerzitien und Missionen der Abstinenz gewidmet ${ }^{34}$.

${ }^{29}$ Por. M. Kalinowski, Duszpasterstwo młodzieży, w: Duszpasterstwo specjalne, red. R. Kamiński, B. Drożdż, Lublin 1998, s. 21.

${ }^{30}$ Zob. B. Kolisko, Praca trzeźwościowa w parafii, Trzeźwymi bądźcie 2 (1983), s. 7-16.

31 Por. Z. Kaniecki, Duszpasterstwo trzeźwości, w: Duszpasterstwo specjalne..., s. $364-365$.

32 Por. S. Wyszyński, Orędzie Pasterskie o trzeźwość w spędzaniu świąt Bożego Narodzenia, Trzeźwymi bądźcie 3 (1986), s. 26.

${ }_{33}$ Zob. M. Dziewiecki, Możliwości duszpasterskie w dziedzinie formowania do trzeźwego stylu życia i zapobiegania zagrożeniom alkoholowym, w: Przestanie nadziei..., s. 118-136.

${ }^{34}$ Por. J. Bartos, Rekolekcje trzeźwościowe w diecezji sandomierskiej, Homo Dei 49 (1980), nr 1, s. 62-65. 
Manche Bischöfe haben angeordnet dass in allen Exerzitien mindestens eine Lehre diesem Problem gewidmet wird ${ }^{35}$.

Die Seelsorge der Abhängigen führen hauptsächlich Diözesen- und Ordenpriester durch. Die Ordensschwestern und Brüder und die Laien erfüllen hier eine Hilfsrolle. Für die Organisation und Koordination der Arbeit in diesen wichtigem Bereich sind in allen Diözesen Seelsorger (oder Referenten) für die Abstinenz verantwortlich, die vom Diözesanbischof ernannt werden ${ }^{36}$.

Die Beteiligung der Personen in diesem Bereich darf man nicht überschätzen ${ }^{37}$ und auch nicht unterschätzen, dennoch ohne des Engagements des Diözesanbischofs kann von einer erfolgreichen Wirkung der Seelsorge der Abhängigen nicht die rede sein, weil, wie schon vor Jahren Kardinal Stefan Wyszynski geschrieben hat dass: „Die gegenwärtige Situation verlangt eine besondere Verstärkung der seelsorgerischen und persönlichen Aufopferung aller Gotteszeugen des Volkes ${ }^{\prime \prime 38}$.

Auch in den Priesterseminaren muss man die Alumnen für die zukünftige seelsorgerische Arbeit mit abhängigen Personen durch Vorlesungen, Teamarbeit in Abstinentgruppen und Fachliteratur, vorbereiten. Im Rahmen der Möglichkeiten wird eine Visitation in der Abstinenzstation vorgeschlagen ${ }^{39}$.

Die Seelsorge Abhängiger umfasst die liebevolle Hirtensorge für die abhängigen Kranken denen man helfen soll sich von der Abhängigkeit zu befreien wie ach für die von Abhängigkeit bedrohten Gläubigen $(\text { Prophylaxe })^{40}$.

Im Rahmen der Seelsorge Abhängiger ist es wichtig bestimmte konkrete Methoden zu anzuwenden. Die Grundlage dafür sind alle schon

${ }^{35}$ Zob. K. Kaniecki, Odpowiedzialność Kościoła płockiego za trzeźwość wiernych w świetle nauczania biskupów płockich w latach 1945-1995, Warszawa 1996.

${ }^{36}$ Zob. R. Rak, Duszpasterstwo w Kościele po II Soborze Watykańskim, Ateneum Kapłańskie 78 (1986), nr 464, s. 102-111.

${ }^{37}$ I to zarówno poprzez inspirowanie przeżycia religijnego osób uzależnionych, ukierunkowującego ich ku wyższym wartościom, jak i poprzez psychoterapię, choćby w „wydaniu amatorskim". Zob. S. Luft, Medycyna..., s. 65.

${ }^{38}$ S. Wyszyński, List do kapłanów w sprawie wzmożenia kościelnej działalności trzeźwościowej, w: Listy Prymasa Polski oraz Episkopatu 1975-1981, Paryż 1988, s. 146.

${ }^{39}$ Zagadnienie to usytuowane jest $\mathrm{w}$ ramach duszpasterstwa specjalistycznego, którego tematyka winna być przedmiotem wykładów z teologii pastoralnej. Zob. R. Rak, Duszpasterstwo specjalistyczne. Założenia i realizacja, Ateneum Kapłańskie 85 (1993), nr 507-508 , s. $258-259$.

${ }^{40}$ Por. U. Dudziak, Człowiek uzależniony..., s. 190. 
vorhandenen Formen der Seelsorge (gewöhnliche Seelsorge) ${ }^{41}$. Die Katecheten müssen sich um den nötigen Platz für diese Thematik, in der Katechisation der Kinder und Jugend ${ }^{42}$, wie auch der Erwachsenen, kümmern ${ }^{43}$.

Die Problematik der Abhängigkeit muss auch in Predigten, Homilien, sowie Standes- und Vorehestandskonferenzen und auch in der Vorbereitung zu anderen Sakramenten, zur Sprache gebracht werden ${ }^{44}$.

Man muss weiterhin die Tradition des Abstinenzversprechens bis zum 18 Lebensjahr von I Kommunionkindern, auch am ersten Jahrestag sowie aus Anlass der Firmung ${ }^{45}$, auch die Gestaltung von alkoholfreien Hochzeitsfeiern, Begräbnissen, Kirmesfeiern, und anderen kirchlichen Festen, aufrecht erhalten, weil sie ein eigenartiges Zeugnis bilden.

Als Auszeichnung für solche Hochzeiten sind schriftliche Segenswünsche für die Ehepaare vom Diözesanbischof. Von den Eltern der Erstkommunionkindern soll man eine Verpflichtung fordern, dass sie für die Erziehung der Kinder in Abstinenz Sorge tragen werden ${ }^{46}$.

Hilfreich für die Abhängigen können Pilgerfahrten und Hingabeakte der Mutter Gottes wie auch die Anbetung des Allerheiligsten Sakraments, Gemeinsames Gebet, persönliche Abstinenz, Entsagung, Formen der Sühne und Wiedergutmachung zu Gott für das, durch den Missbrauch angerichtetes, Unheil (z.B. Abstinenzzirkel, Kreuzzug für Befreiung des Menschen, Bewegung für die Erneuerung der Kirche).

$\mathrm{Zu}$ den wichtigsten Pilgerfahrten in den letzten Jahren gehören die Gesamtpolnische Pilgerfahrt des Abstinenzapostolats nach Tschenstochau am III Samstag und Sonntag im Juni. Seit mehreren Jahren gehen Pilger zu Fuß in Intention der Abstinenz des Volkes nach Niepokalanów.

${ }^{41}$ Por. Z. Kaniecki, Duszpasterstwo trzeźzoości, w: Duszpasterstwo specjalne..., s. 356-357; zob. E. Walewander, Wychowanie chrześcijańskie w nauczaniu i praktyce Kościoła Katolickiego na ziemiach polskich w II potowie XIX wieku, Lublin 1994, s. 126.

${ }^{42}$ Aby ustrzec się niebezpieczeństwa stworzenia atmosfery konsumpcji alkoholu lub innych środków psychotropowych, zwłaszcza przez dzieci i młodzież, potrzeba, aby głoszący słowo Boże dawał dobry przykład $\mathrm{w}$ tej dziedzinie. Wówczas będzie on realizował wychowawczą zasadę zgodności praktyki z teorią życia i głoszoną ideą. Zob. S. Tarasiuk, Bądźcie trzeźwi i czuwajcie!, Olsztyn 1970, s. 21-26, 31-35.

${ }^{43}$ Por. S. Luft, Medycyna..., s. 67

${ }^{44}$ Duszpasterstwo, które jest apostolstwem zmierzającym do wolności od uzależnień, winno być prowadzone przede wszystkim $\mathrm{w}$ ramach duszpasterstwa zwyczajnego, albowiem formy tego duszpasterstwa dotyczą wszystkich ludzi. Zob. R. Kamiński, Działalność duszpasterska w dużym mieście, Roczniki Teologiczne 43 (1996), nr 6, s. 180.

${ }^{45}$ Por. Z. Mazur, Przyrzeczenie trzeźwości z okazji pierwszego petnego uczestnictwa we mszy św. Katecheta 3 (1976), s. 125.

${ }^{46}$ Zob. Wytyczne Episkopatu Polski dla kościelnej działalności trzeźwościowej, Ateneum Kapłańskie 66 (1974), nr 394, s. 263-264. 
Den II Samstag und Sonntag in August treffen sich in Niepokalanów die Mitglieder des Kreuzzuges für Befreiung der Menschen auf ihrer alljährlichen Pilgerfahrt. Es gibt überdies viele diözesane Pilgerfahrten ${ }^{47}$.

Alle Gläubigen sollen zu Abstinenzversprechen mit Andeutung auf die Liebe zu Gott und das Glück der Familie ermuntert werden.

Es wird angewiesen, dass die betreffende Person vor dem Leisten des Versprechens, durch einen Facharzt untersucht wird. Den Versprechen leistenden muss man in das Abstinenzpfarrbuch eintragen ${ }^{48}$.

Die von Alkohol und Drogen abhängigen Personen und ihre Familien sollten mit spezieller Fürsorge betreut werden. In den Pfarrgemeinden sollten Abstinenzkreuzzüge namens $\mathrm{Hl}$. Maximilian Kolbe gegründet werden sowie Räumlichkeiten für Treffen von Gruppen Anonymer Alkoholiker zur Verfügung gestellt werden und man soll die in der Pfarrgemeinde existierenden Clubs der Abstinenten in Obhut nehmen ${ }^{49}$.

Eine wertvolle Erfahrung der Arbeit mit Alkoholabhängigen sind in den Diözesen im Advent und in der Fastenzeit organisierte Exerzitien, für Anonyme Alkoholiker und ihre Familien wie auch Besinnungstage (2 Tage im Jahr verbunden mit dem Sakrament der Beichte und der Buße).

\section{ABSCHLUSS}

Die pastorale Theologie erinnert uns, dass das Ziel der Seelsorge die Führung, der in verschiedenen Verflechtungen der gesellschaftlichen Beziehungen lebenden Menschen, die der Beeinflussung verschiedener sozialer und ideologischer Ströme der Zeit unterliegen, zum Treffen mit Gott im Glauben und Liebe, ist (vrg. KDK 11).

In der katholischen Kirche war immer das Bedürfnis der Rede und hauptsächlich des Handelns für kranke und durch andere Probleme des Lebens heimgesuchte Menschen (vrg. KK 37). Auch viele moderne Menschen sind Heute durch schmerzliche, schwer zu ertragene Ereignisse des individuellen und gesellschaftlichen Lebens, betroffen ${ }^{50}$.

Der abhängige Mensch genötigt durch toxische Substanzen wie nur zu erwähnen Drogen, Alkohol erweckt verschiedene Reaktionen: Widerwille

${ }^{47}$ Por. K. Kaniecki, Z. Kaniecki, Piesza pielgrzymka w intencji trzeźwości Narodu, Słowo - Dziennik Katolicki 21 (1995), s. 21.

${ }^{48}$ Por. D. Zawitkowski, Ksiegga Trzeźwości, Trzeźwymi bądźcie 5 (1983), s. 28-29.

${ }^{49}$ Zob. S. Luft, Medycyna..., s. 59-62.

${ }^{50}$ Por. Jan Paweł II, Przemówienie podczas spotkania z osobami starymi, chorymi i ułomnymi (Wiedeń, 1 IX 1983), L'Osservatore Romano 4 (1983), nr 9, s. 10. 
(„,hast was du willst“), Gleichgültigkeit („was geht mich das an, sollen das Spezialisten regeln“), Verdrängen, Verlagerung („,bei uns kommt das nicht vor") $^{\prime \prime}$ sowie wirkliche oder falsche Hilfe („,man muss sie bedauern und eine Therapie durchführen“ $)^{51}$.

Man muss bedauern, dass diese Leute nicht früher in solche religiöse Bewegungen trafen, denn eine tiefe geistige Formation und ein richtiger Zeitvertreib sind Faktoren, die sie sicherlich von der Versklavung durch die Sucht bewahren würden.

Es ist wahr, das von Jahr zu Jahr die Zahl der Menschen die spezieller Hilfe und Sorge brauchen steigt, denn die Liste der verschiedenen Pathologien in Polen und auf der Welt wird länger. Es kommt ein Problem zum Vorschein, dass man nicht verschweigen oder nicht wahrnehmen kann. Man muss ihnen zu Hilfe kommen.

Schon die ältesten christlichen Schriften unterstreichen die Notwendigkeit der Fürsorge für diese Menschen. Der Autor von „Pasterz" Hermas (II n.Chr.) kritisiert z.B. die, die beim Anhäufen von Reichtum von den Nächsten in Not vergessen. In der über zweitausendjährigen Geschichte hat die Kirche immer an den Grundsatz Christi gedacht: "denn nach dem Maß, mit dem ihr messt und zuteilt, wird auch euch zugeteilt werden" (Łk 6, 38).

Die Seelsorge der Abhängigen, die heute "das gute Teil” des ganzen pastoralen Wirkens der Kirche ist, müsste demnach in das Leben dieser Kirche ein tieferes Verständnis dieses Geheimnisses Jesu Christi einbringen. Sie sollte auch ein besonderes Zeichen der Gegenwart der Kirche in der heutigen Welt werden, die sich auf individuelles, egoistisches und utilitaristisches Streben konzentriert und das Bewusstsein der theologischen Liebe verliert - die durch die Gegenwart Christi in jedem und hauptsächlich in dem Hilfe brauchenden Menschen begründet ist - für die Sache des raffinierten, oft berechnenden Altruismus ${ }^{52}$.

Die Liebe, die ein Prüfstein unserer Christlichkeit und Menschlichkeit ist beweist sich in schwierigen Situationen (vrg. Łk 6, 38).

Diese Regel sollte demnach auch die Mission der katholischen Kirche in Polen und in der Welt gestalten, die u.A. die seelsorgerische Mission für die Abhängigen auf sich nimmt, und jederzeit sich dieser Herausforderung stellen muss ${ }^{53}$.

${ }^{51}$ Por. U. Dudziak, Człowiek uzależniony..., s. 189.

${ }^{52}$ Zob. Myśli Matki Teresy, Warszawa 1998.

${ }^{53}$ Zob. J. S. Pelczar, Zarys dziejów miłosierdzia w Kościele katolickim, Kraków 1916, s. $48 \mathrm{nn}$ 


\section{DUSZPASTERSKA MISJA KOŚCIOŁA WOBEC OSÓB UZALEŻNIONYCH}

\section{STRESZCZENIE}

Kościół, jak podkreśla konstytucja dogmatyczna Lumen gentium, otrzymał od swego Założyciela, Jezusa Chrystusa, misję głoszenia Królestwa Bożego wśród narodów i stanowi zaczątek tego Królestwa na ziemi (por. KK, nr 5). Zachęcony przykładem Chrystusa, pozostaje on również stale otwarty na potrzeby każdego człowieka. Misja zbawcza Kościoła dotyczy jednak nie tylko wieczności człowieka, ale także pełni jego rozwoju doczesnego.

Ta misja opiera się ponadto m.in. na stałym urzeczywistnianiu posługi Chrystusa na rzecz osób uzależnionych od alkoholu, papierosów i innych środków psychoaktywnych. Ukazanie realizacji tego zadania w ramach ogólnej działalności duszpasterskiej Kościoła stało się przedmiotem niniejszego artykułu, który nosi tytuł: „Duszpasterska misja Kościoła wobec osób uzależnionych".

Rzeczywistością kryjącą się pod tą nazwą jest każda działalność Kościoła, mająca na celu przyjście z pomocą tym osobom, usuniętym często na margines życia społecznego (por. Mt 18, 12; Łk 19, 10), w celu uchronienia ich przed dalszym pogłębieniem się uzależnienia i pomocy im w powrocie do normalnego, zdrowego życia. 
